\title{
IT INNOVATION THROUGH A WORK SYSTEMS LENS
}

\author{
Steven Alter \\ School of Business and Management, University of San Francisco, USA
}

\begin{abstract}
This paper presents what I think is an innovation, the use of work system concepts as a lens for understanding IT innovation in organizations. It starts by presenting the ideas at the heart of the work system approach, the work system framework for describing an existing or proposed work system and the work system life cycle model for describing how work systems change over time. To demonstrate how a work system lens can illuminate both practice and theory related to IT innovation in organizations, it returns to the previous IFIP 8.6 Conference (Copenhagen, October 2003) and applies work system ideas to the situations and theories in the papers presented there. It closes by using CASE adoption as a final example about IT innovation within IT groups.
\end{abstract}

Key words: IT innovation, adoption, work system, system development, implementation, actor network theory, work system framework, work system life cycle model

\section{INTRODUCTION}

This paper presents what I think is an innovation, the use of work system concepts as a lens for understanding IT innovation in organizations. This approach builds on the term work system, which has been used by a number of socio-technical researchers and by some practitioners for over 20 years, but has not been defined carefully or used as a rigorous concept until recently. The term work system appeared in two articles in the first volume of MIS Quarterly [Bostrom and Heinen, 1979a, 1979b]. Mumford and Weir [1979, p. 3] spoke of "the design and implementation of a new work system." Davis and Taylor [1979, p. xv] mentioned "attempts at comprehensive work systems design, including the social systems within which the work systems are embedded." For other past uses of the term work system see Alter (2003). 
This paper addresses a number of points in the Call for Papers, including ontological issues about the meaning of IT innovation, perceptions of IT innovation, and the observation that "successful innovations in IT, unlike those in consumer markets, must work through the dynamics of the organization." The concepts presented apply equally to internal innovation within IT groups and to innovations in business functions supported by IT groups. Regardless of whether the focus is an IT group attempting to implement OOP or a sales organization trying to implement CRM, IT innovation in organizations is about doing work differently.

Understanding IT innovation from a work system viewpoint is consistent with the observation by Brynjolfsson (2003) that "for every dollar of IT hardware capital that a company owns, there are up to $\$ 9$ of IT-related intangible assets, such as human capital -- the capitalized value of training -and organizational capital -- the capitalized value of investments in new business-process and other organizational practices. Not only do companies spend far more on these investments than on computers themselves, but investors also attach a larger value to them." If this ratio is even close to correct, a totally IT-centric view of IT innovation is bound to ignore or underplay important aspects of how IT innovations succeed, survive without success, or simply die in organizations.

This paper shows that an IT-centric view of IT innovation is self-limiting and inherently biased. For example, why should an IT professional or anyone else view IT innovation within organizations (as opposed to a new chip inside a computer) as being about IT? Except possibly from the viewpoint of vendors trying to sell specific commercial products, IT innovation is about improving business operations and business results. This paper develops this point by showing that thinking about IT innovation from a work system viewpoint might generate new insights and new ways to make IT innovations more successful.

The paper proceeds as follows: The next section presents the ideas at the heart of the work system approach, the work system framework for describing an existing or proposed work system and the work system life cycle model for describing how work systems change over time. To demonstrate how a work system lens can illuminate both practice and theory related to IT innovation in organizations, it returns to the previous IFIP 8.6 Conference (Copenhagen, October 2003) and applies work system ideas to a variety of situations and theories in papers presented there. It closes by using CASE adoption as a final example about IT innovation within IT groups. 


\section{THE WORK SYSTEM FRAMEWORK AND WORK SYSTEM LIFE CYCLE MODEL}

A work system is a system in which human participants and/or machines perform work using information, technology, and other resources to produce products and/or services for internal or external customers. Typical business organizations contain work systems that procure materials from suppliers, produce products, deliver products to customers, find customers, create financial reports, hire employees, coordinate work across departments, and perform many other functions. It is possible to view an entire organization, firm, or even an industry in work system terms, but that is not the intention here. We view organizations as consisting of multiple work systems rather than as a single, large work system combining many independent or partly dependent business processes and groups of participants. On the other hand, a work system such as a supply chain or other interorganizational system can extend across multiple business enterprises.

Identifying and organizing work system concepts is one part of a long term project attempting to develop "the work system method," a broadly applicable set of ideas that use the concept of work system as the focal point for understanding, analyzing, and improving systems in organizations, whether or not IT is involved. The work system method includes both a static view of a current (or proposed) system in operation and a dynamic view of how a system evolves over time through planned change and unplanned adaptations. These views are summarized in Figures 1 and 2, whose specific terms are explained succinctly in Alter (2002). A subsequent switch from "business process" to "work practices" is explained in Alter (2003).

The static view is summarized as the work system framework (Figure 1), which identifies the basic elements for understanding and evaluating a work system. The work system itself consists the four elements inside the large trapezoid. The other five elements must be included in even a rudimentary understanding of a work system's operation, context, and significance. This framework is prescriptive enough to help in describing the system being studied, identifying problems and opportunities, describing possible changes, and tracing likely impacts as changes propagate across the system. An immediate implication is that business and IT professionals discussing a real world situation should avoid focusing solely on information needs, computerized information, or IT. 


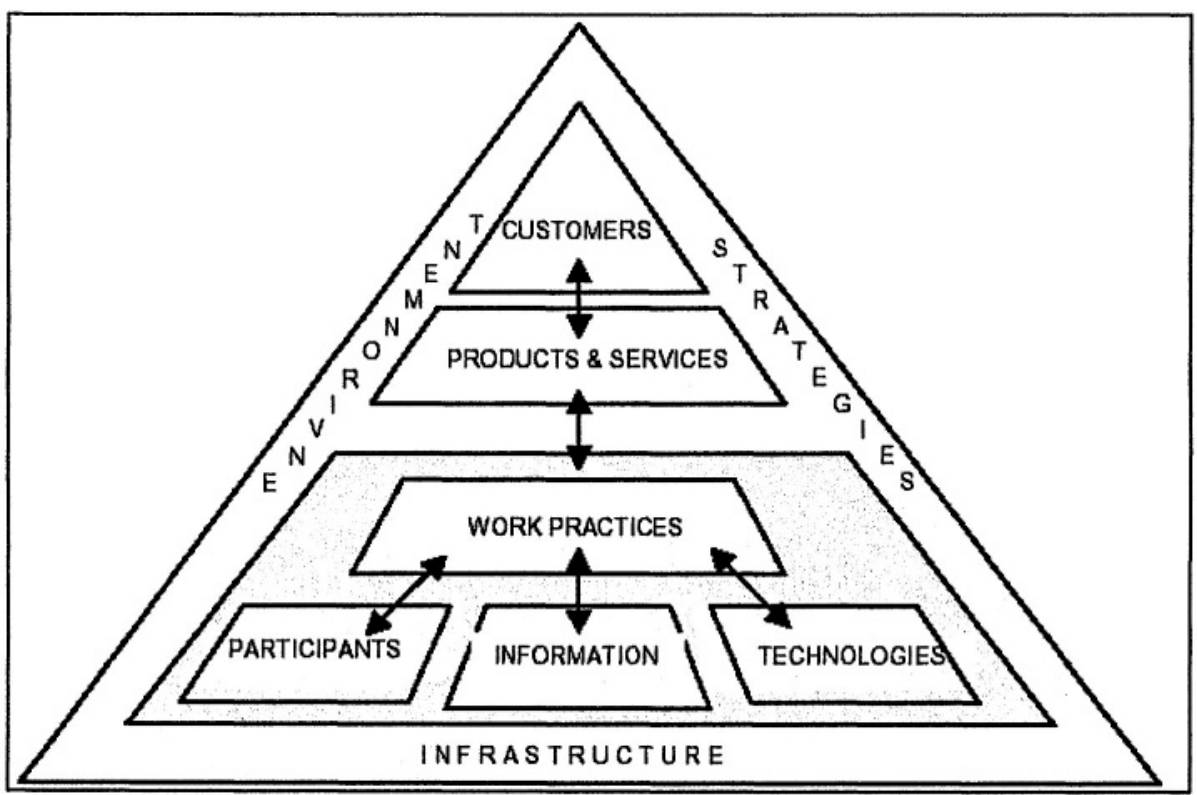

Figure 1. The Work System Framework

The dynamic view is based on the work system life cycle model (Figure 2), which shows how a work system may evolve through multiple iterations of four phases. This life cycle model encompasses both planned and unplanned change, and differs substantially from project models that are often called life cycle models when applied to software projects. Planned change in an established organization typically starts from a work system whose operation or relationship to other systems requires improvements that involve more than small adapations. The initiation phase identifies the problem or opportunity, the general approach, and the necessary resources. The development phase acquires, modifies, or creates hardware, software, and other resources needed before the revised system can be implemented in the organization. The implementation phase ends with acceptance of the new work system, and another operation and maintenance phase begins.

The arrows in the work system life cycle model represent the fact that change may occur at three levels:

1. Incremental adaptations and small changes that tend to be unplanned and localized, and can occur during any of the four phases.

2. Projects that accomplish planned changes in the work system.

3. Evolutionary change that occurs through multiple iterations of planned and unplanned change. IT innovation is frequently a key enabler of a new iteration, although some iterations may be driven by other issues, such as an organizational change or changes in the external environment. 


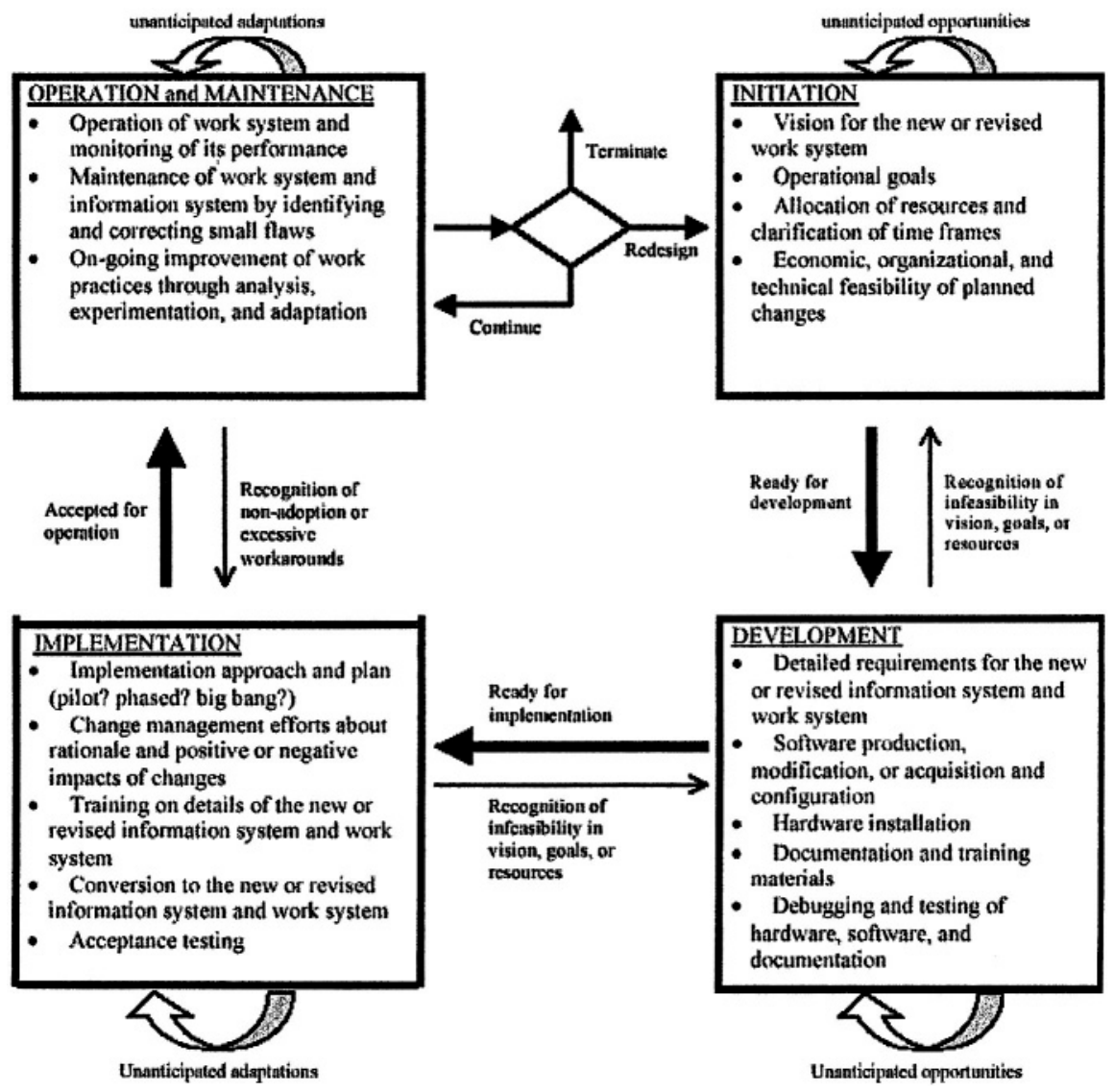

Figure 2. The Work System Life Cycle Model

Combining work system concepts with general problem solving ideas yields a systems analysis method that avoids separating social and technical analysis (in contrast, see Mumford and Weir (1979, p. 29) or Taylor and Felten (1993, p. 5)), is more prescriptive than soft systems methodology (Checkland, 1999), and is less detail-oriented than tools for specifying procedures, database structures, or computer programs. The static and dynamic views can be used together in a systems analysis method that treats the information system as part of the work system until a final step when it distinguishes between work system changes that do and do not involve the information system. A unique aspect of this method (in comparison with other systems analysis methods for information systems) is its explicit use of principles that describe a typical system's desired behavior and results. After the system and problem or opportunity are described, the principles are used to examine the current system, to help identify potential improvements, 
to explore whether potential improvements in one area might cause problems elsewhere, and to sanity-check the recommendation.

The concept of work system is a general case of systems operating in organizations. Special cases of work systems include information systems, projects, value chains, supply chains, and totally automated work systems. These and other special cases should inherit most of the properties of work systems, which include success factors, risk factors, and generalizations related to efficiency and effectiveness. (Alter, 2002; 2003; 2004)

The purpose of most information systems is to support one or more work systems. Although information systems and the work systems they support were often quite separable decades ago when most business computing was still card-based and batch-oriented, today many important information systems overlap significantly with the work systems they serve. For example, in a payroll system or ecommerce web site that sells and downloads software, most or all of the work system is an information system. In work systems related to producing, transforming, or delivering physical things, information systems may play a less dominant role even if they are essential for a work system's effective operation and success. And in extreme cases such as highly automated manufacturing, the information system and work system overlap so much that the manufacturing is largely controlled by the information system. Turn off the information system and this type of manufacturing grinds to a halt.

\section{VIEWING LAST YEAR'S IFIP 8.6 PAPERS THROUGH A WORK SYSTEM LENS}

One way to demonstrate the potential usefulness of the work system lens is to show its broad applicability to the situations described in papers from last year's IFIP 8.6 conference, Diffusion and Adoption of Networked Information Technologies, in Copenhagen, Oct. 6-8, 2003. Although the following discussion shows that the work system approach contains ideas that help any business or IT professional identify key issues related to IT innovation, I make no claim that similar ideas have never been stated. Consider several excerpts from the papers:

"It is necessary that the members of the human organization express a great amount of care to incorporate the new system into their daily work life. To reach a full appropriation of the system, the involved actors should engage actively to cope with the involved uncertainties and not rely on a passive detached process of acknowledgement. (Ciborra, 1996)" (cited by Nilsson et al 2003) 
"It seems that we -- as a professional community of system developers -tend to treat the systems as separate units from the work activities, stressing the development of computer-based artefact much more than the development of work (Forsman and Nurminem, 1994). However, as soon as we change our scope from the computer artefact to the activity itself, the information system can be seen as a means of structuring and developing a social system. (Nurminem, 1988)" (cited by Heikkilä et at, 2003, p. 2)

The uniqueness of the work system approach lies in its attempt to combine and amplify selected ideas from sociotechnical analysis, implementation studies, organization behavior, and project management to make them readily usable by typical business and IT professionals trying to describe and understand systems in organizations. In terms of IT innovation, the work system approach says that IT implementation or IT diffusion is not the problem. The problem is improving specific work systems. Accordingly, one should start the analysis with the work system, not the IT innovation.

Next we present direct or indirect evidence of the applicability of work system ideas to situations in 9 of the 11 papers presented at the Copenhagen conference. The other two papers concerned stakeholder theory and the possibility of buyers shaping IT markets.

\subsection{IT innovations in healthcare}

Applying a work system lens to compare accounts of three situations related to healthcare reveals striking similarities. The situations were the of a large Swedish hospital's radiology department (Nilsson, Grisot, and Mathiassen, 2003), elderly care in Trondheim, Norway (Lines, Viborg Andersen, and Monteiro, 2003) and elderly care in a Swedish locality (Hedström, 2003).

An initial step in analyzing any work system is to use the work system framework (Figure 1) to summarize the work practices, participants, information, and technology. In the radiology department, the work system was about entering orders for radiology services. The existing work system used paper-based orders, with the conveniences and shortcomings of paper. Switching to an electronic ordering system would impose more structure and would absorb more physician time in entering all orders, but ideally would improve consistency and reliability in recordkeeping. In the two elderly care situations, the information system provided administrative information and supported caregivers. In both cases, the work system seemed nebulous. If there was an intention to support care giving, it wasn't clear exactly how the 
information system was supposed to help. Similarly, even the administrative information to be recorded was unclear from the accounts.

Applying the work system life cycle model (Figure 2) to the situations leads one to look for the initiation, development, and implementation phases. In all three cases, the initiation phase seemed distant from most participants. In one elderly care situation, the decision was attributed to "politicians," implying that little or no analysis of work systems took place. In all three situations, the development phase involved acquiring software produced elsewhere, but it was unclear whether that software was configured to suit local situations. All three accounts described attempts to implement the information system before competing an analysis of how it would be integrated into the work practices. There was little or no effort to identify how the information system would help the work system participants or to reconcile divergent stakeholder interests prior to implementation.

Based on the above, just using Figure 1 and Figure 2 at various times as these situations unfolded would have immediately identified significant problems that should have been resolved before implementation. At minimum, attention to the most basic work system concepts might have been a reminder about simple principles that anyone can apply, but that seem not to have been applied by the main protagonists in these cases:

- Work practices: Don't assume that an IT innovation will fix a work system if you can't or won't define that work system.

- Participants: Don't assume that all work system participants will find a particular IT innovation valuable. Recognize that incentives matter.

- Information: Don't assume that IT innovations necessarily provide better information.

- Technology: Don't assume that IT innovations always help. IT innovations may absorb effort rather than reducing it.

- Customers: Recognize that different work system customers and other stakeholders have different objectives and priorities.

- Initiation phase: Make sure stakeholders including work system participants or their representatives are involved. Obtain agreement about the need to change the work system and about intentions to enforce changes or allow change to occur voluntarily.

- Development phase: Make sure the hardware and software fit the situation.

- Implementation phase: Before implementing make sure all participants will either benefit directly or will have a strong reason to play their roles. 


\subsection{IT innovations related to interorganizational systems or eGovernment}

As with the papers about healthcare, the theme of inadequate work system definition was found in these three papers. For example, a particular interorganizational information system, "was built to support the execution of work-tasks performed according to the process descriptions, but failed to take into account the fact that in the field the processes for executing different work-tasks, possibly because of long-term relationships between organization A and some of its suppliers, varies by suppliers." (Heikkilä et al, 2003) The issue about process descriptions not matching work practices has been described by ethnographic researchers for decades. Any description of a real world system is only an approximation, but settling for the idealized business process, an approximation that is likely to be inaccurate, seems a recipe for creating implementation problems when work system participants discover the mismatch between the IT innovation and their reality.

A study of the diffusion of ICTs in small to medium enterprises (SMEs) in Italian industrial districts found that most firms had adopted relatively simple technologies such as email, ISDN, and websites, but had not adopted complex technologies that require deeper work system analysis, such as ERP, EDI, or ecommerce. Unlike simple technologies, complex technologies require substantial work system analysis before they can be implemented and used effectively. Despite general reluctance, "technology providers and SMEs themselves have started to pay greater attention to internal process reconfiguration in order to deal with the actual competitive challenges in the market: globalisation, quality standards, time-to-market, variety and differentiation of the production." (Muzzi and Kautz, 2003) Contrary to the largely voluntary technology adoption in the three healthcare examples, competitive pressure is forcing Italian SMEs to adopt IT innovations they may not prefer. A related example in the United States is Wal-Mart's directive to its top 100 suppliers to attach RFID tags to every box and pallet shipped to Wal-Mart by January 2005. Smaller suppliers have until 2006. "Flout Wal-Mart's orders and 'you potentially get thrown off the shelf of the largest retailer in the world." (Boyle, 2003) In work system terms, adopting RFID is an attempt by Wal-Mart to improve inventory management work systems. The improved work systems include new work practices enabled by RFID, new roles, abilities, and incentives of work system participants, new information encoded on the tags, new technology for reading the tags, new infrastructure supporting the entire effort, and a business environment in which large retailers are trying to force compliance with desired technical and physical standards. Future IT innovations by Italian SMEs need to 
conform to work practices, information requirements, and technology standards imposed downward by retailers.

Finally, Sørgaard (2003) notes that ambitions for e-government "are often unrealistic, and that political goals seem to dominate over effective, stepwise approaches to coordination. On a pragmatic level, there is a need to focus on simpler, process-oriented mechanisms for coordination ..." In other words, whether or not e-government seems an attractive banner to march under, the real progress will occur through analyzing and improving specific work systems that span organizations.

\subsection{An IT innovation to support virtual workplaces}

A study of the diffusion of the virtual workspace product Lotus QuickPlace in a large European financial institution found that different adoption situations "differed to such a degree that the it is problematic to denote it as one single innovation. (Billeskov Bøving and Bødker, 2003) Thus, the sale of Lotus QuickPlace, an IT innovation from a vendor's viewpoint, might be viewed more realistically as an opportunity to improve the performance of specific work systems that differ substantially. Each implementation effort might be viewed as a separate IT innovation.

"The decision to introduce the QP technology" ... was taken without thorough studies of needs and possibilities." It was a quick and dirty, web based approach that needed "no integration with existing security infrastructures" and "could be implemented very quickly from an IT operations point of view." Analysis after 10 months showed a large percentage of dead (unused) documents. Initial use of QP for a virtual workplace occurred 37 times, but sustained use occurred in around a third of the cases. In many instances, use of QP was intertwined with competing or supplementary media such as email or telephone, illustrating that IT innovation involves much more than diffusion of a technical artifact. "The DOI [diffusion of innovation] framework -- when applied to the diffusion of a collaborative technology -- overlooks, however, a second innovation process ... [that] does not come from a central source, but is based on local situated actions. It is the innovations produced when groups of people agree on using the technology to support novel protocols (in the words of CSCW) or genres (in the words of genre theory)." (Billeskov Bøving and Bødker, 2003) The second innovation process is work system innovation, partly represented in the work system life cycle model as the small adaptations denoted by the inwardly directed arrows going back into each phase. 


\subsection{Paper about application service providers}

To an outsourcer, an application service provider (ASP) provides IT services that would be difficult or impractical to provide using internal resources. From the ASPs viewpoint, its job is to provide those services through its particular work systems. As defined by Johansson (2003), "an ASP enterprise [is] a third patty firm that deploys, manages, and remotely hosts software applications through centrally located data centers on a payas-you-use basis," A detailed look at an ASP would find work systems for deploying and managing software, hosting software applications, performing client billing and performing other necessary functions. Many of those work systems are largely automated due to the nature of the services an ASP provides. A large part of the IT innovation of creating an ASP is creating and managing those work systems, each of which evolves through the same phases and adaptations that characterize the evolution of any work system.

Table 1. Reasons for Project Success and Failure in Projects cited by Pries-Heje (2003), organized by phase of the work system life cycle

\begin{tabular}{|c|c|c|}
\hline & In successful projects & In unsuccessful projects \\
\hline $\begin{array}{l}\text { Initiation } \\
\text { phase }\end{array}$ & & $\begin{array}{l}\text { - No one responsible for } \\
\text { whole diffusion process } \\
\text { - No one with in-depth } \\
\text { knowledge }\end{array}$ \\
\hline $\begin{array}{l}\text { Development } \\
\text { phase }\end{array}$ & $\begin{array}{l}\text { - User expectations harmonized early in the } \\
\text { project } \\
\text { - System and workflow matched each other }\end{array}$ & $\begin{array}{l}\text { - Written documentation } \\
\text { unfit for use } \\
\text { - Totally new graphical } \\
\text { interface } \\
\text { - Rushing to meet over } \\
\text { optimistic estimates, } \\
\text { developers produced a } \\
\text { system filled with defects }\end{array}$ \\
\hline $\begin{array}{l}\text { Implementatio } \\
n \text { phase }\end{array}$ & $\begin{array}{l}\text { - Implementation planned long in advance } \\
\text { - Training developed and given to target users } \\
\text { - Managers prepared for dialogue with } \\
\text { associates } \\
\text { - Effective communication with users } \\
\text { - Pilot users involved early } \\
\text { - Top management backing } \\
\text { - Quality meetings }\end{array}$ & $\begin{array}{l}\text { - Training months before } \\
\text { the system was launched } \\
\text { - Training rushed and } \\
\text { presented when many } \\
\text { users were on holiday. } \\
\text { - User expectations not } \\
\text { met }\end{array}$ \\
\hline $\begin{array}{l}\text { Operation } \\
\text { and } \\
\text { Maintenance } \\
\text { phase }\end{array}$ & $\begin{array}{l}\text { - Effective support strategy } \\
\text { - Technology intuitive to use } \\
\text { - Technology transparent to users } \\
\text { - Clear advantages and time savings for the } \\
\text { users (work system participants) }\end{array}$ & $\begin{array}{l}\text { - Inadequate resources for } \\
\text { the system } \\
\text { - Not possible to print } \\
\text { screen content for lack } \\
\text { of color printers }\end{array}$ \\
\hline
\end{tabular}




\subsection{Paper about stakeholders roles in successful and unsuccessful projects}

As part of the background for a discussion of stakeholder roles, PriesHeje, (2003) compared five successful versus unsuccessful diffusion and implementation projects. Table 1 lists the reasons for success and failure, categorized by phase of the WSLC. In some instances, it was unclear whether a particular factor such as "top management backing" pertained mostly to a particular phase or applied across all the phases.

\section{SEEING ORGANIZATIONAL INNOVATION THROUGH A WORK SYSTEM LENS, WHETHER OR NOT INFORMATION TECHNOLOGY IS INVOLVED}

The previous section demonstrated that Figures 1 and 2 could be applied readily to the situations discussed in papers in the 2003 IFIP 8.6 working conference. This section explores ramifications of using a work system lens to understand IT innovation. It covers topics including different views of IT innovation, the possibility of measuring the size of an IT innovation, and a comparison with other frameworks for exploring IT innovation.

\subsection{IT Innovation: Thing or Process? About IT or about a Work System?}

Table 2 compares four views of IT innovation based on two distinctions: (1) IT innovation can be viewed as a process or as a thing and (2) IT innovation can be about IT or about a work system. The four views are named the vendor view, the diffusion view, the work system view, and the organizational change view.

The views in Table 2 have different associations. The vendor view initially focuses on product engineering and later focuses on sales and marketing. The diffusion view focuses on communication, awareness, beliefs concerning early or late adoption, and individual choice. The work system view is about organizational performance. The organizational change view is about how organizations change over time.

All of these views are linked. For example, a vendor's success depends on diffusion of products in a marketplace. For IT products used in organizations, success depends on whether they are incorporated into work systems (or into infrastructure that is hidden from work system participants.) 
Similarly, in an organizational context (when usage is not voluntary and independent), the diffusion view merges into the work system as product awareness leads to adoption and usage. Links in the opposite direction are also worth noting because many work system innovations would never be imagined or realized without the vendor efforts to create products and raise awareness, and without diffusion phenomena that spread awareness and demonstrate potential applicability. Because we are focusing on IT innovation in organizations, we will pursue the work system and organizational change views.

Table 2. Comparing four views of IT innovation

\begin{tabular}{|c|c|c|}
\hline & Innovation as a thing & Innovation as a process \\
\hline $\begin{array}{l}\text { The innovation is } \\
\text { about IT }\end{array}$ & $\begin{array}{l}\text { Vendor View: The } \\
\text { innovation is a change in } \\
\text { hardware and/or software. } \\
\text { Example: a new computer } \\
\text { chip that uses less energy }\end{array}$ & $\begin{array}{l}\text { Diffusion view: The process is the } \\
\text { diffusion of usage of the hardware } \\
\text { and/or software } \\
\text { Example: Process by which } \\
\text { teenagers adopt cellphone } \\
\text { cameras. }\end{array}$ \\
\hline $\begin{array}{l}\text { The innovation is } \\
\text { about a work system }\end{array}$ & $\begin{array}{l}\text { Work system view: The } \\
\text { innovation is a change in a } \\
\text { work system } \\
\text { Example: Improvement in } \\
\text { inventory tracking through } \\
\text { use of RFID tags. }\end{array}$ & $\begin{array}{l}\text { Organizational change view: The } \\
\text { innovation is a process of } \\
\text { changing a work system } \\
\text { Example: Process of changing } \\
\text { from an old inventory system to a } \\
\text { new inventory system. }\end{array}$ \\
\hline
\end{tabular}

From a work system viewpoint, an IT innovation is a change in a work system that is unique enough to be called an innovation in the setting. Although IT innovations always involve IT in some way, they can actually start in different parts of a work system. For example:

- Starting from technology: New technology (such as RFID tags) or better use of existing technology (such as fuller use of Word templates) makes it possible to change work practices.

- Starting from information: Intention to use different information or provide information in a different form or level of detail (e.g., new graphics or new ETL (extract, text, load) requirements in a data warehouse) leads to innovative use of existing or new technology.

- Starting from participants: Enrolling tech-savvy participants or providing training on technology in a work system leads to new possibilities for doing work differently (e.g., train CAD users to use more capabilities of software that they have used at a $20 \%$ level for the last three years).

- Starting from work practices: Change the business process or change aspects of sense making and articulation work that make it possible to use technology more effectively for better results (e.g., change from assembly line logic to case manager logic). 
- Starting from the products and services: Improve a work system's products and services by incorporating digitized information or even new IT hardware that provides additional value for customers (e.g., present bills electronically, provide automatic analysis of bills).

The assumption that IT innovation need not start with IT might seem unusual, or possibly self-contradictory, but this broader view could motivate deeper understandings of important phenomena. For example, better understanding of complementary efforts, assets, and investments related to IT diffusion and assimilation might help IT vendors provide more value for their customers through better, more adaptable products and better help in configuring and using those products to make more of a difference for users.

\subsection{IT Innovation as Technology Upgrade or Work System Change?}

Previous comments about successful and unsuccessful projects mentioned by Pries-Hege (2003) indicate that the phases in the work system life cycle model map to real situations involving IT innovation. Comments about negotiation and accommodation in that paper and other conference papers are consistent with inclusion of Figure 2's inwardly curved arrows that represent unplanned incremental changes and adaptations. To look at life cycle issues further, consider the distinction between innovations that are technology upgrades and innovations that are changes in work practices.

In a technology upgrade, the users often continue doing the same work in basically the same way, but with better tools. Such technology upgrades are less disruptive than changes in work practices because the upgrades can be accomplished as a technical task. The simplest changes of this type might be called "plug-ins" because the change is accomplished by substituting a tool (e.g., a cellphone or computer chip) with greater capabilities for another tool having lesser capabilities. Upgrades that require parameter-drive tailoring to the specifics of the situation (e.g., upgrade to a new personal computer) might be called "plug-in and configure." In both cases, an upgrade process almost transparent to the user might provide significant benefits in costeffectiveness plus access to infrequently used features or capabilities.

In a work system change involving more than a technology upgrade, the innovation is visible to the users and may require substantial change by users. Alternative processes for innovations of this type include "acquire, configure, and implement" and "design, build, and implement." ERP and CRM projects exemplify the first type of process; building a new software application for internal company use exemplifies the second. The advantages and disadvantages of acquiring commercial application software versus building customized software are well know and will not be discussed here. 
Although pure versions of those processes differ substantially, success in each case depends on up-front analysis that improves fit to reality, assures technical quality prior to implementation, and facilitates implementation. Both the technical upgrade processes and the work practice change processes fit directly into the work system life cycle model.

\subsection{Is it Possible to Measure the Size of an IT Innovation?}

The foregoing qualitative distinction between technology upgrades and work practice changes did not try to quantify the extent of changes related to an IT innovation in an organization. Although an innovation's success is often measured as changes in costs, productivity, or output, performance measures such as these do not describe the size of the changes an IT innovation enables. A work system approach might help in quantifying the size of an organizational IT innovation because larger organizational changes generate higher levels of inherent risk, resistance, and controversy.

It is not obvious how to compute the size of an IT innovation. The degree of change in the technology itself says little about the extent of effects felt by work system participants. The planned monetary expenditure and the number of people whose work practices will change are partial characterizations of the amount of change, but each has shortcomings. Brynjolfsson (2003) notes that the vast majority of expenditures on IT innovations are for complementary processes, assets, and knowhow, rather than for technology. Many of those expenditures are hidden in operational budgets not designed to highlight efforts absorbed by changing work practices. Estimates based on the number of people whose work practices change may be misleading because that number may not reflect the extent or significance of the change. In addition, implementation efforts required for similar changes in different organizations differ based on factors including the quality of leadership, the organization's recent history, organizational inertia, and personal aversion to change in those organizations.

The work system framework leads to preliminary ideas that can only be sketched here, but that indicate possible directions for developing usable measures based on the following 3 assumptions:

1. Innovation is more than change. Innovation is change in a direction that is unfamiliar in the setting. Thus, an ERP implementation in a company might be an innovation even today after hundreds of companies have taken that path. If innovation were limited to first time inventions or contemporaneous second tries, recognizing an innovation would require global knowledge of all comparable situations. 
2. Innovation is gauged by the degree of newness in the changes introduced across the work system, not just within a particular element such as the technology. The earlier example of RFID tags shows that these changes occur throughout the work system:

- new IT and non-IT technology (such as the physical layout required by the limitations of RFID transmission),

- new information made available

- change in work practices to use the information and accommodate the technology

- change in the knowledge and capabilities of the participants

- change in the products and services produced by the work system.

3. The size of a work system is related to the number of participant hours devoted to the work system within the relevant time frame. This gives equal weighting to participant hours for all participants, but recognizes that some work system participants may contribute to many different work systems during any week (e.g., during a week a manager may plan for the future, help subordinates do their work, and serve on external task forces). Note that the participant hours are hours performing the work in the operational system, not hours devoted to creating that system.

Ignoring typical concerns about scaling, assume that all of the changes and newness measures are expressed in a numerical scale from 0 to $\mathrm{n}$. The size of an IT innovation can be quantified roughly as follows:

Size of innovation $=$

\{WSsize $X$ \{WP newness $\mathrm{X}$ \{sum of other newness $\}$, where

- WS Size = work system size, measured as the number of participant hours used in the work system's operation within the relevant time frame

- WP newness $=$ the newness of the work practices

- Sum of other newness = sum of the newness within four other work system elements, technology, information, participants, products and services.

Although not a definitive in a mathematical sense, the formula represents a direction for comparing the size of IT innovations. It implies:

- IT innovations are not just about introduction of new IT.

- Major IT innovations tend to affect every aspect of a work system.

- A major change in IT infrastructure hidden from the users (e.g., new middleware) is a small IT innovation in an organizational sense.

- An IT innovation that is visible to users could still be a small innovation in an organizational sense if there is little change in work practices, such as when new laptops perform existing functions or when new application software is configured to replicate existing work practices. 
- Introduction of new application infrastructures such as ERP affect many work systems. Therefore the scale of change for an ERP introduction may be orders of magnitude greater than the scale of change for localized software innovations or new communication technologies such as instant messaging whose usage is voluntary.

- IT innovations introduced without reference to an existing or planned work system have a higher probability of being ignored or having little impact. (e.g., previously mentioned examples related to healthcare systems and Lotus QuickPlace)

\subsection{Does the Work System Lens Fit with Other Frameworks for Exploring IT Innovation?}

The various papers presented at the 2003 IFIP 8.6 meeting mentioned a number of methodologies and theories including actor network theory, diffusion of innovation (DOI), soft system methodology (SSM), and several models of stages of implementation. Comparing some of these with the work system lens helps in recognizing its generality and limitations.

\subsubsection{Comparison with Actor Network Theory}

Actor network theory (ANT) models the process of organizational change as a set of interactions among different actors.

"ANT develops from the idea that entities take their form and acquire their attributes as a result of their relations with other entities (Law, 1999). In this scheme entities have no inherent qualities as being large or small, human or nonhuman, etc., but rather, as Law points out, such divisions or distinctions are understood as effects or outcomes. They achieve their form as a consequence of the relations in which they are located." (Nilsson et al, 2003)

The non-human actors can include technology and infrastructure:

"Modern technology will, at least as seen from each organization or each government, appear as an independent actor (Monteiro, 2000)" ...... "Ciborra (2000) argues that since an information infrastructure is so deeply sunk into social practices and shaped by factors not in control by one company, it makes sense to view an information infrastructure as an actor and to describe the relationship between a company and the infrastructure as more symmetrical.” (cited by Sørgaard, 2003)

If a work system's technology can be viewed as an actor and the infrastructure that supports it can be viewed as an actor, it is possible that an 
entire work system and its specific elements such as work practices, information, and products and services can be viewed as actors in the actornetwork. Further, the principle of alignment says that these elements change over time (through the planned and unplanned change in Figure 2) in order to remain aligned internally and externally.

Accordingly, it is possible to say that the work system framework identifies classes of actors that should be considered in the actor-network, and further, that the arrows within the work system framework (Figure 1) indicate principle vectors along which those specific actors should align. From this perspective, the work system framework might be seen as a template for identifying relevant actors for an ANT analysis related to an IT innovation. Similarly, the work system life cycle model could be useful in describing part of the path along which the actor network will travel as it negotiates and configures the role of an IT innovation or rejects it. Thus, ANT might provide a vocabulary and analytical approach that supports the use of work system concepts. In return, work system concepts might identify likely classes of actors in an ANT analysis of an IT innovation.

\subsubsection{Comparison with Soft System Methodology (SSM)}

SSM is a method for defining and analyzing system-related problems and opportunities. Checkland (1999, pp. A3-A15) notes that SSM has evolved over three decades. An iterative seven-stage methodology (p. 163) emerged during the 1970s only to be revised as four main activities (p. A15):

1. "Finding out about the problem situation, including culturally/ politically;

2. Formulating some relevant purposeful activity models;

3. Debating the situation, using models, seeking from that debate both (a) changes which would improve the situation and are regarded as both desirable and (culturally) feasible and (b) the accommodations between conflicting interests which will enable action-to-improve to be taken;

4. Taking action in the situation to bring about improvement."

SSM calls for thinking about the "root definitions" of systems in terms of a set of elements somewhat similar to those of the work system framework (Figure 1). The corresponding elements in SSM have the acronym CATWOE, which stands for customers, actors, transformation process, Weltanschauung (world view), owner, and environmental constraints.

The work system approach tries to be more prescriptive than SSM through the use of pre-defined frameworks for describing a system (Figure 1 ) and how it evolves over time (Figure 2). Not discussed in this paper, the work system approach also calls for explicit use of work system principles and a large number of system concepts in a semi-structured systems analysis 
approach. (Alter, 2002). The system concepts are being compiled and organized as "Sysperanto," an ontology of the IS field that is currently under development. (Alter, 2004)

\subsubsection{Comparison with Innovation or Implementation Models}

The IFIP 8.6 papers from 2003 also mention the diffusion of innovation model (DOI) plus several other innovation or implementation-related models that can be compared with the work system life cycle model (WSLC).

Diffusion of innovation (DOI) theory is centered on the diffusion of technical innovation. The spotlight is on the technology, with the implicit assumption that technology users have the right to adopt it or not. This assumption is incorrect in many situations in which users must adopt the technology in order to play their roles as work system participants. The work system approach avoids a technology-focused view of change by assuming that an IT innovation must be assimilated into a work system to survive forces of rejection and attain significant impact. Accordingly, diffusionrelated phenomena such as path dependence and windows of opportunity (Tyre and Orlikowski, 1993) can be interpreted in terms of the details of the development and implementation phases of the WSLC. Similarly, assimilation gaps (Fichman and Kemerer, 1999) and marketing "chasms" (Moore, 1991) can be interpreted as a summation of occurrences and nonoccurrences across work systems that might adopt a particular technology.

Nilsson et al (2003) mention Swanson's (2001) “concept of innovation processes as a story having four phases: comprehension, adoption, implementation, and assimilation." The phases of the WSLC are directly comparable with Swanson's four phases. Initiation corresponds with comprehension, but development involves much more than adoption. Adoption sounds as though the crux of the matter is acceptance or rejection of a technical option. In contrast, the development phase might involve acquiring and configuring hardware and software, but might also involve building custom software. Implementation is the third phase of both, but operation and maintenance extends further in time than assimilation. The WSLC assumes that operation and maintenance continues with current technologies until another iteration of the cycle begins.

Figure 1 in Heikkilä et al (2003) is "an IS implementation process" that proceeds through four phases, planning, procurement, implementation, and use. Because this focuses on IS implementation rather than phases of innovation processes, it is closer to the WSLC model than Swanson's model (above). An important difference, however, is that the IS implementation model assumes that the topic is an information system that is being implemented and then "used" in the final phase. Although the WSLC can be 
used to describe an information system project (because an information system is a special case of work system), the WSLC is designed to describe the evolution of any work system. Furthermore, as information systems are increasingly integrated with the work systems they support, the idea of information system "use," rather like use of a hammer or lawn mower, is increasingly less realistic.

\section{A FINAL EXAMPLE: IT INNOVATION IN IT GROUPS}

Instead of closing by summarizing the foregoing discussion, we will look at one more example, the disappointing adoption of an IT innovation called CASE (computer aided software engineering) technology. It once seemed that CASE would be "the new big thing," and that it would revolutionize system development in IT groups. The promise and hype were great, but the extent of adoption has been disappointing, as demonstrated by a lengthy "assimilation gap" between acquisition of CASE and use for 25\% of new applications. (Fichman and Kemerer 1999) Based on data through 1993, after 54 months only $24 \%$ of CASE acquisitions in their survey had resulted in that level of use. Around the same time, Orlikowski (1993) compared two CASE implementations and concluded that "the adoption and use of CASE tools should be conceptualized as a form of organizational change and that such a perspective allows us to anticipate, explain, and evaluate different experiences and consequences following the introduction of CASE tools in organizations." Noting that "even with its many benefits, most organizations have found it difficult to implement CASE," Sumner and Ryan (1994) tried to find an explanation by identifying critical success factors in information systems analysis and design and determining whether CASE tools support these critical success factors." They concluded that CASE tools support technical analysis, the identification of "the processes and data which are needed for correct task accomplishment by the work system [that is being improved]," but that "social analysis is not well-supported by existing CASE tools." Furthermore, looking at the work within the IS organization, they concluded, "for CASE to be effective, an organization may need to view information systems development as a work system."

The basic questions that might have been asked to assess CASE as an IT innovation are the same as the questions that should be asked when thinking about improving any work system, whether or not IT is involved and whether or not the setting is an IT group or another area of the business:

- What is the work system, how well does it operate, and how well should it operate? 
- How good are the work system's products and services, and how good should they be?

- Within the work system, what are the strengths and shortcomings of current work practices, technology, information, and staffing?

- What are the desired changes in work practices, products and services, information, and technology?

- What will the work system participants have to learn and how will they be motivated to change?

Thinking about CASE (or any other technology) as an IT innovation to be diffused, installed, or adopted does not address these practical issues with enough force and direction. Following an IT innovation from the original inspiration to the reality of better performance requires something like a work system approach.

\section{REFERENCES}

Alter, S. (2002) "The Work System Method for Understanding Information Systems and Information Systems Research", Communications of the AIS 9(6), pp. 90-104

Alter, S. (2003) "18 Reasons why IT-Reliant Work Systems Should Replace the IT Artifact as the Core Subject Matter of the IS Field," Communications of the AIS, 12(23), pp. 365394

Alter, S. (2004) "Sysperanto - A Theory-Based Ontology of the IS Field," Under review.

Billeskov Bøving, K. and Bødker, K. (2003) "Where is the Innovation? The Adoption of Virtual Workspaces," IFIP 8.6 Working Conference on Diffusion and Adoption of Networked Information Technologies, Copenhagen, Denmark, Oct. 6-8.

Bostrom, R.P. and J.S. Heinen (1977a), "MIS Problems and Failures: A Socio-Technical Perspective. PART I: The Causes." MIS Quarterly, 1(3), December 1997, pp. 17-32.

Bostrom, R. P. and J. S. Heinen (1977b), "MIS Problems and Failures: A Socio-Technical Perspective. PART II: The Application of Socio-Technical Theory." MIS Quarterly, 1(4), December 1997, pp. 11-28.

Boyle, M. (2003) "Wal-Mart keeps the change," Fortune, Nov. 10, 2003, p. 46.

Brynjolffson, E. (2003) “The IT Productivity Gap," Optimize, Issue 21, July 2003, accessed at http://www.optimizemag.com/issue/021/roi.htm on Oct. 20, 2003

Checkland, P. (1999) Systems Thinking, Systems Practice, Chichester, UK: John Wiley.

Ciborra, C., (1996), "Introduction: what does groupware mean for for the organization hosting it?" in Groupware and Teamwork. Invisible aid or technical hindrance? edited by C.Ciborra, J.Wiley and Sons.

Davis, L.E. and J.C. Taylor eds. (1979) Design of Jobs, $2^{\text {nd }}$ ed., Santa Monica, CA: Goodyear Publishing Company.

Fichman, R.G. and Kemerer, C.F., (1999) "The Illusory Diffusion of Innovation: An Examination of Assimilation Gaps," Information Systems Research, (10:3), Sept. 1999, 255-275.

Foreman U., \& Nurminen M.I. (1994). "Reversed Quality Life Cycle Model,” in Human Factors in Organizational Design and Management - IV, Bradley G.E., and Hendrick H.W., eds., Elsevier Science B.V., 393-398. 
Hedström, K, (2003) The Socio-Political Construction of CareSys: How Interest and Values Influence Computerization," IFIP 8.6 Working Conference on Diffusion and Adoption of Networked Information Technologies, Copenhagen, Denmark, Oct. 6-8.

Heikkilä, J., Vahtera, H, and Reijonen, P., (2003) "Taking Organizational Implementation Seriously: The Case of IOS Implementation," IFIP 8.6 Working Conference on Diffusion and Adoption of Networked Information Technologies, Copenhagen, Denmark, Oct. 6-8.

Johansson, B. (2003) "Exploring Application Service Provision: Adoption of the ASP Concept for Provision of ICTs," IFIP 8.6 Working Conference on Diffusion and Adoption of Networked Information Technologies, Copenhagen, Denmark, Oct. 6-8.

Law, J. (1999) “After ANT: complexity, naming, and topology," in Actor Network Theory and After, ed. By J, Law and J. Hassard, Blackwell Publishers.

Lines, K., Viborg Andersen, K. and Monteiro, E., (2003) "MIS and the Dynamics of Legitimacy in Health Care," IFIP 8.6 Working Conference on Diffusion and Adoption of Networked Information Technologies, Copenhagen, Denmark, Oct. 6-8.

Moore, G.A. (1991) Crossing the Chasm, HarperCollins.

Mumford, E. (2000) "Socio-technical Design: An Unfulfilled Promise?" Proceedings of IFIP W.G.8.2 Working Conference 2000, IS2000: The Social and Organizational Perspective on Research and Practice in Information Systems, Aalberg, Denmark, June 2000.

Muzzi, C. and Kautz, K., (2003) "Information and Communication Technologies Diffusion in Industrial Districts: An Interpretive Approach," IFIP 8.6 Working Conference on Diffusion and Adoption of Networked Information Technologies, Copenhagen, Denmark, Oct. 6-8.

Nilsson, A, Grisot, M. and Mathiassen, L. (2003) "Imposed Configurations by Networked Technology," IFIP 8.6 Working Conference on Diffusion and Adoption of Networked Information Technologies, Copenhagen, Denmark, Oct. 6-8.

Nurminen M.I., (1988). "People or Computers: Three Ways of Looking at Information Systems", Studentlitteratur, 1988

Orlikowski, W.J. (1993) "CASE Tools as Organizational Change: Investigating Incremental and Radical Changes in Systems Development," MIS Quarterly, Sept. 1993, pp. 309-340.

Pries-Heje, J. (2003) "Modeling the Primary Stakeholders in IT Diffusion and Adoption," IFIP 8.6 Working Conference on Diffusion and Adoption of Networked Information Technologies, Copenhagen, Denmark, Oct. 6-8.

Sørgaard, P. (2003) "Management and Co-ordination of eGovernment," IFIP 8.6 Working Conference on Diffusion and Adoption of Networked Information Technologies, Copenhagen, Denmark, Oct. 6-8.

Sumner, M. and Ryan, T. (1994) "The impact of CASE: Can it achieve critical success factors?" Journal of Systems Management, 45(6), pg. 16, 6 pages.

Swanson, E.G. (2001) "Telling an Innovation Story," in Diffusing Software Product and Process Innovations, eds., M.A. Ardis and B.L. Marcolin, Kluwer Academic Publishers

Taylor, J.C. and Felten, D. F. (1993) Performance by Design: Sociotechnical Systems in North America, Englewood Cliffs, NJ: Prentice-Hall, 1993

Tyre, M.J. and Orlikowski, W.J. (1993) "Windows of Opportunity: Temporal Patterns of Technological Adaptation in Organizations," Organizational Science, 5(1), 1994, pp. 98118. 